\title{
Condiciones y características del surgimiento y desarrollo de la organización Tupac Amaru en Argentina
}

Recibido: 24 de marzo 2018

Revisado: 21 de mayo 2018

Aprobado: 25 de junio 2018

Melina Gaona

Argentina. Doctora en comunicación. Becaria postdoctoral CONICET

(Consejo Nacional de Investigaciones Científicas y

Tecnológicas) y la Universidad Nacional de Quilmes. Profesora de la Universidad Nacional de La Matanza. Ex profesora en la

Universidad Nacional de Jujuy y la Universidad Nacional de Tierra del Fuego. Ex becaria de la Cátedra Regional UNESCO Mujer, Ciencia y Tecnología y ex becaria doctoral de CONICET. Se enfoca en estudios de género, de sectores populares y de movimientos sociales desde la crítica cultural. Correo electrónico: melina.d.gaona@gmail.com

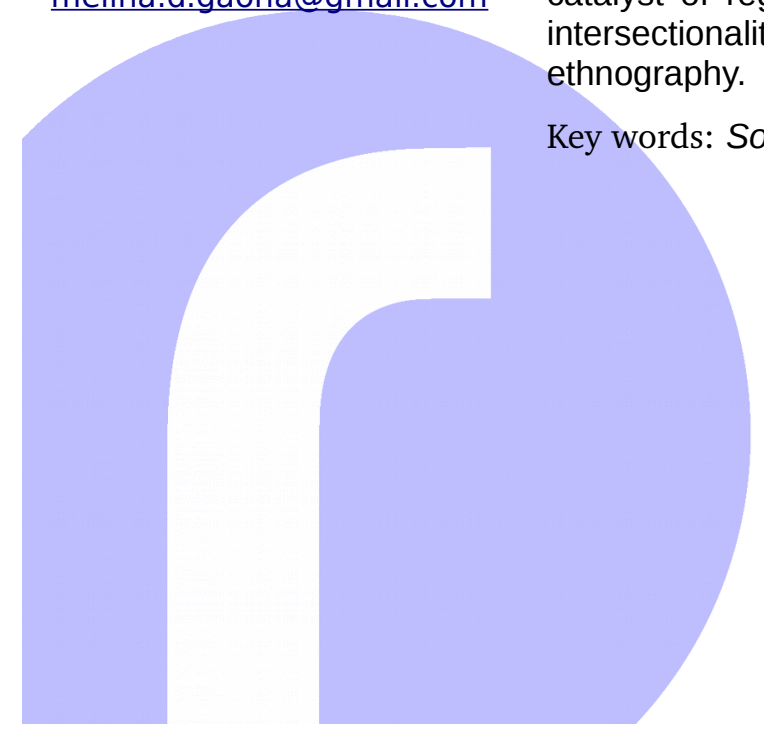

http://investiga.uned.ac.cr/rupturas/ ethnography.
Resumen: El artículo es un análisis sociocultural de la organización Tupac Amaru, en el noroeste argentino, que busca: 1) reconstruir las condiciones materiales que permitieron el surgimiento de un movimiento multitudinario de características populistas; y 2) interpretar distintas dimensiones de las demandas y la estructuración de lazos sociales al interior del movimiento social. Esta caracterización pretende echar luz sobre parte de los factores que dieron curso tanto a su explosión multitudinaria y productiva como a su posterior estigmatización y condena. Se propone considerar a la organización como una catalizadora de conflictos históricos regionales, e indagar de manera crítica las distintas demandas a partir de un análisis desde la interseccionalidad identitaria de sus militantes. La investigación está basada en un acercamiento etnográfico multisituado.

Palabras clave: Movimientos sociales; populismos; interseccionalidades

\section{Conditions and Characteristics of the Emergence and Development of the Social Organization Tupac Amaru in Argentina}

Abstract: This is a socio-cultural analysis on the social organization Tupac Amaru in northwest Argentina. It seeks 1) to unravel the factors that led to the emergence of this populist movement, and 2) to interpret different dimensions on their demands and the way they build their ties within the social organization. This characterization seeks to bring light to the factors that led to its massive emergence and productive burst, as well as its subsequent stigmatization and conviction. As a result we consider the organization to be a catalyst of regional historical conflicts; and understand its demands by the intersectionality of its militants. This research is based on a multi-sited

Key words: Social movements; populism; intersectionalities 


\section{Introducción}

Este trabajo se presenta como un análisis sociocultural en línea de tiempo acerca de un fenómeno popular con carácter regional, pero que sin dudas ha traspasado las fronteras locales y nacionales, para convertirse en un foco para el análisis de los movimientos sociales latinoamericanos en el nuevo siglo. A la luz de un proceso histórico como el mencionado, buscamos desarrollar analíticamente las condiciones históricas que dieron curso al surgimiento y desarrollo de la organización barrial Tupac Amaru en Jujuy, región noroeste de Argentina. A este análisis de sus condiciones históricas se le suma una interpretación de las principales características que reúne este movimiento social, y los puntos nodales que llevaron a convertirlo en una organización tan destacada y relevante, como polémica y perseguida.

La organización barrial Tupac Amaru es un movimiento asambleario de sectores urbanos empobrecidos, surgido en el filo entre el siglo XX y XXI. Probablemente por ello se nutra de tradiciones políticas históricas como el peronismo, los populismos latinoamericanos y el indigenismo; y haga parte innovadora en demandas identitarias más vinculadas a las ciudadanías personalistas de este siglo. Este cruce, sin perder de foco los términos comunitarios andinos sobre los que han librado sus vínculos al interior, y las complejidades de su relación con las distintas esferas del Estado, ya lo convierten en un acontecimiento sociocultural notorio para la pesquisa. Más aún, el suceso del encarcelamiento de su líder, Milagro Sala, en el marco de una protesta pacífica a principios de 2016, la ha llevado a convertirse en un símbolo cargado de disputas en torno de los derechos humanos, los límites del Estado y las precariedades de los movimientos populistas.

La región jujeña se imprime como condicionante de las contradicciones visibles en la organización desde un primer momento. La provincia se encuentra ubicada en la frontera norte argentina, limita con Chile y Bolivia, tiene una alta incidencia de población indígena, y su participación en los destinos productivos, políticos y económicos del país ha sido históricamente periférica. La capital de la provincia, San Salvador de Jujuy, ha sido la cuna en la que surgió y se desarrolló buena parte del movimiento Tupac Amaru, aunando sobre todo a decenas de miles de personas provenientes de los asentamientos populares urbanos.

La historia de Jujuy es una historia de las desigualdades, y de los distintos factores que hacen de capas que van tramando complejamente esas desigualdades al tener presente que no solo observamos brechas económicas, sino la incidencia que tienen distintas inequidades vinculadas sobre todo al plano identitario de la experiencia. La Tupac Amaru bucea en ese entramado, y su hacer parece haber encontrado una función transformadora de esas desigualdades. Este movimiento se cimienta de manera coherente con la histo- 
ria social y cultural local, pero apela a subvertir algunas dimensiones del reparto material, a la vez que ciertos valores simbólicos.

Los resultados y las reflexiones expuestas en este artículo fueron construidos desde una tarea etnográfica y hermenéutica, parte de una tesis doctoral que analizó a la Tupac Amaru como catalizadora de conflictos históricos y del presente acerca de lo hegemónico, la interseccionalidad de la diferencia y los lazos sociales. Las claves del proceder multitudinario, la vehemencia de su liderazgo y la articulación de reacciones hacia ellos son un nuevo zócalo para la lectura de los movimientos sociales y de los procesos populares en estas latitudes.

Para la prosecución de los objetivos planteados en este artículo, se han analizado los datos producidos en entrevistas y observaciones participantes en campo; la sistematización de registros audiovisuales mediáticos y virtuales; la recopilación de ordenanzas, leyes y programas nacionales y provinciales; y la indagación en pronunciamientos oficiales por parte de organismos nacionales e internacionales.

\section{Condiciones de surgimiento}

La presidencia de Carlos Saúl Menem durante la última década del pasado siglo significó para una provincia como Jujuy, signada por las asimetrías históricas a raíz de la postergación económica regional, un recrudecimiento del estancamiento previo en el crecimiento industrial local. El experimento desregulador del mercado de los ' 90 , el desfinanciamiento de la seguridad social y el desguace y posterior venta de las empresas públicas propició el incremento de los índices de desigualdad iniciados hacía décadas en una provincia sin inserción productiva clara en el nuevo modelo, fomentando altísimos niveles de desempleo, exclusión y marginalidad (Lagos y Gutiérrez, 2009). Un buen número de la población involucrada en los sectores productivos truncados ya para fines de los ' 80 y principios de los ' 90 se vio obligada a recurrir al cuentapropismo, a los microemprendimientos y a la dependencia de diferentes paliativos estatales (Bergesio, Golovanevsky y Marcoleri, 2009). Este proceso y otros similares de supresión del empleo generaron una escalada conflictiva en los sectores urbanos de la provincia que se instalaron mediante luchas crónicas a lo largo de toda la década de los '90 en forma de piquetes, manifestaciones, huelgas, tomas y acampes. Entre 1980 y 2002, de las provincias del Noroeste del país, las cuales muestran niveles más bajos de producción y empleo que el resto del territorio, Jujuy registró la tasa de actividad promedio y de empleo más bajas de la región (Martínez, Golovanevsky y Medina, 2010).

La experiencia a nivel nacional de inestabilidad y crisis económica más pronunciada desde mediados de la década de los '90, y la exacerbación de crisis institucional durante el gobierno de De la Rúa se experimentó en Jujuy desde fines de los '80 y durante todos los '90, con un clima creciente de empobrecimiento e "ingobernabilidad" (Lagos y Gutiérrez 2009, p. 102). Esto 
1. Ricardo De Aparici renuncia (1987-1990); Eduardo Huáscar Alderete completa el mandato del anterior (1990-1991); Roberto Rubén Domínguez renuncia (1991-1993); José Carlos Ficoseco renuncia (1992-1994); Oscar Agustín Perassi completa el mandato de los dos anteriores (19941995); Guillermo Eugenio Snopek fallece (1995-1996); Carlos Alfonso Ferraro renuncia (1996-1998); Eduardo Alfredo Fellner completa el mandato, y es electo y reelecto (1998-2007). provocó que la provincia se ajustara políticamente al tránsito de ocho gobernadores a lo largo de la década, con una caída virulenta y conflictiva en el caso de cuatro de ellos $^{1}$ (Lagos y Gutiérrez 2006). De hecho, para 2001 y 2002, el declive económico nacional se experimentó como línea de continuidad de un conflicto de muy larga data que, en cambio, encontró a Jujuy en una relativa estabilidad gubernamental habiendo sostenido por primera vez en varios años a un mismo gobernador en el poder.

No obstante, la crisis económica se sostuvo como marca estructural de la experiencia local y la población bajo la línea de pobreza para ese año alcanzaba un 68,1\%, de acuerdo con el INDEC (Lagos y Gutiérrez 2009). La situación productiva va de la mano con problemáticas habitacionales y urbanas vinculadas a la periferización de la ciudad, debido a las migraciones internas. García Vargas (2009) habla de una "implosión de pobres" (p.367) como fenómeno social local a partir del drenaje poblacional de las zonas rurales de quebrada y puna hacia conglomerados urbanos de los valles. El epicentro paradigmático de este proceso es Alto Comedero, un sector populoso y popular que en alrededor de 25 años alcanzó a reunir prácticamente un tercio de la población de todo San Salvador de Jujuy.

Al fragor de este panorama económico y político, la beligerancia social e inestabilidad gubernamental posicionaron al movimiento de desocupados y a una parte de los sindicatos estatales como un emergente popular. Kindgard (2009) reconoce que la tendencia alineada con el gobierno en aquellos años por parte de la histórica Confederación General del Trabajo (CGT) generó la necesidad de la expresión de demanda y de lucha a partir de nuevos sindicatos disidentes: el Movimiento de Trabajadores Argentinos (MTA), la Corriente Clasista y Combativa (CCC) y la central obrera independiente Central de Trabajadores de la Argentina (CTA). En Jujuy, por aquellos años, tiene una gran preponderancia el Frente de Gremios Estatales (FGE), el cual, entre otros gremios, contaba con el Sindicato de Empleados y Obreros Municipales (SEOM). Otra de las configuraciones claves de la época a nivel político es la Multisectorial, compuesta por sindicatos, organizaciones de estudiantes y colegios profesionales.

Los diferentes frentes políticos con una amplia red de articulación de demandas sociales se convierten, entonces, en un destacado eje de resistencia frente a gobiernos provinciales débiles con un marcado uso de la fuerza oficial para combatir la protesta.

\section{Características del movimiento}

Frente a un gobierno justicialista caudillista que responde a los rumbos federales sin un fuerte peso de reconocimiento y legitimidad local, y al presentarse en las últimas décadas un panorama desmovilizante por parte de los cuadros desde los partidos tradicionales, podemos considerar que la historia política de Jujuy reciente se ve plenamente guiada por la lucha de los movimientos sociales: sindicales, de organizaciones piqueteras, del movimiento 
indígena y del movimiento de derechos humanos(Karasik y Gómez 2015; Gaona y López 2013; Kindgard 2009; Rodríguez Blanco 2002).

En este contexto, los cimientos de lo que hoy se conoce como parte de la organización barrial Tupac Amaru tienen origen en la labor encauzada desde los sindicatos de la Asociación de Trabajadores del Estado (ATE) y la Central de Trabajadores de la Argentina (CTA) a partir de 1999. La CTA nació como central sindical autónoma y alternativa, disidente y desasociada de los sindicatos identificados con el peronismo de izquierda, y contraria a las políticas neoliberales acentuadas en la década de 1990. Aunque es una central sindical, desde sus orígenes reúne características 'movimientistas' por su composición, formas de lucha y prácticas asamblearias. Podría definirse como un "movimiento social sindical" (Waterman citado en Giorgetti 2015, p.4). La CTA, reconocida como organización sindical de tercer grado (central que congrega a sindicatos del sector, los que a su vez incorporan a organizaciones de base), reúne a nivel nacional a dos de los sindicatos más afectados por las políticas de Reforma de los '90, la Asociación de Trabajadores del Estado (ATE) y La Confederación de Trabajadores de la Educación de la República Argentina (CTERA).

La inserción de muchos de los militantes y dirigentes de la organización tiene inicio a fines de la década de los '80, integrándose a las líneas de ATE. La acción colectiva territorial se ve así marcada históricamente por sus orígenes sindicales y en torno de la demanda al Estado. Desde la gestación del movimiento podemos distinguir cuatro vías de inscripción política claves para la interpretación de esta organización. Las primeras tres se refieren a la raíz combativa sindical de origen, el corte peronista con el que se identificaban muchos de sus militantes ${ }^{2}$, y la importancia de la inscripción territorial barrial cotidiana. Estos tres elementos son comunes a la Tupac Amaru y a muchas organizaciones sociales a nivel nacional. A estas características de pertenencia hay que sumarle un factor poco explorado, incorporado o asimilado en lo que tiene que ver con las organizaciones de este tipo a nivel federal, y que probablemente haga de la Tupac Amaru una experiencia singular. Este es el factor indígena coya y guaraní, y su trascendencia como real matriz ideológica en muchos de los cursos de la organización (Dujovne Ortíz 2017; Gaona, 2017). ${ }^{3}$ La histórica "etnificación de las categorías laborales" (Karasik 2005, p.101) a nivel local permitió una confluencia 'natural' entre militancias de clase y demandas étnicas.

En 2003, con la aprobación para participar del Programa Federal de Emergencia Habitacional ${ }^{4}$ y la organización de cooperativas de construcción de viviendas, la Tupac Amaru accede a su primera experiencia de manejo autónomo de fondos genuinos dispuestos directamente desde el Estado Nacional para la producción, y con ello se da una escalada exponencial de crecimiento en los cursos políticos de movilización popular.

El escenario histórico planteado como parte inicial del texto sirve para poder sopesar la relevancia de la organización a nivel provincial, en una economía monopolizada por el sector productivo privado que requiere mano de obra muchas veces mal remunerada y en condiciones paupérrimas de trabajo
2. Sin embargo, se hallaban ante un gobierno peronista a nivel provincial y nacional que desconocía la tendencia histórica del movimiento en favor de los trabajadores y los sectores más vulnerables (Kindgard 2009), lo que desdibujaba así el horizonte partidario como fórmula de la acción militante por el sostenimiento de dichos principios.

3. Por el proceso histórico de estructuración social del trabajo a nivel provincial, el encuentro de los componentes étnicos con componentes de clase no es casual ni menor. De acuerdo con lo propuesto por Karasik (2005), hay una inscripción material y simbólica de lo étnico en el universo socioeconómico de Jujuy que se ha traducido desde entonces en una coacción subalternizante.

4."El Programa busca solucionar la emergencia habitacional y laboral a través de la participación de los beneficiarios del Plan Jefes y Jefas de Hogar y

desocupados, organizados en forma de Cooperativas de Trabajo, para la construcción de viviendas. De esta manera, la política del programa resuelve simultáneamente problemas habitacionales y laborales, permitiendo aplicar fondos, actualmente destinados a subsidios por desempleo en la emergencia, a la generación de un proceso productivo que permita la reinserción social y laboral". (Fuente:

http://www.vivienda.gob.ar/eme rgencia/descripcion.html 
(sector azucarero, tabacalero y minero). Así, la Tupac Amaru se convirtió rápidamente en uno de los motores económicos de la provincia, ubicándose como el tercer empleador, solo detrás de la industria azucarera y del Estado.

Como muestra material puede enumerarse, a grandes rasgos, que en la provincia desde la organización se construyeron ocho mil viviendas, dos escuelas y colegios primarios y secundarios, un instituto de estudios terciarios, centros de salud, un centro de rehabilitación médica integral, centros integrales comunitarios, salas de cuidado de la infancia, comedores, polideportivos y piletas, un centro cultural con cine, el parque acuático más grande de la provincia y una réplica del templo de Kalasasaya (originalmente en Tiwanaku, Bolivia). Esta tarea se llevó a cabo en cooperativas de construcción generadas en gran medida por mujeres sin experiencia previa en albañilería.

Desde fines de la primera década del 2000, la Tupac Amaru sostiene el peso de interlocutor local vital frente a la política tradicional, voz mayúscula entre las organizaciones sociales de la región e inclinador de la balanza de la Central de Trabajadores Argentinos a nivel federal (aportando más de 70 mil afiliados a la CTA). Esta tendencia se sostiene hasta septiembre de 2010 cuando la Tupac decide abandonar su afiliación a la Central, luego de un conflicto de apoyos en las elecciones internas llevadas adelante entre los candidatos Hugo Yasky y Pablo Micheli. Es además desde estos años una intermediadora fundamental de los recursos disponibles por medio de distintos programas de política pública nacional y actora de roce internacional con movimientos políticos afines en toda Latinoamérica.

El contacto con distintas organizaciones latinoamericanas de base, sindicatos y diversos movimientos de derechos humanos llevó a solidificar las características de un movimiento con demandas de clase que supo reconocer el entroncamiento material de distintos factores que acrecientan los vínculos desiguales. Esto refiere a que estratégicamente supieron demandar sobre todo al Estado, políticas de reparación y redistribución en razón de su posición como trabajadores y trabajadoras desocupadas, como indígenas, como mujeres y miembros de la comunidad LGBT, y como demandantes en las luchas por la Memoria, la Verdad y la Justicia frente a la última dictadura.

Esto devino en un crecimiento escalonado y la acumulación de un capital simbólico que se fue evidenciando de manera más pronunciada a lo largo de los años. La gestión frente al Estado, la alineación convencida a la par de un modelo de gobierno a nivel nacional y las modulaciones estratégicas en la disputa con el poder político provincial, le permitieron consolidarse como vía hegemónica alternativa, tanto en lo que refiere al desarrollo material a partir de los recursos del Estado como a la disposición masiva de militantes políticos reunidos en causas comunes (Battezatti 2012; Gaona 2016).

Ya establecida como fuerza alternativa y síntesis simbólica de los deseos y demandas de un fragmento de los sectores populares locales, la Tupac Amaru dio varias muestras de su capacidad de convocatoria y peso político organizando la Constituyente Social en 2008, la marcha de los pueblos originarios en el bicentenario argentino en 2010, y conformando un partido político y 
frente electoral -el Partido por la Soberanía Popular (PSP) y el Frente Unidos y Organizados por la Soberanía Popular (FUyO)- a partir de 2013. La conformación del movimiento en tanto que partido político tiene la rúbrica de ambas expresiones: las bases de la justicia social peronista y la raíz comunal andina. Esta indigenización del peronismo le agrega a la cuota histórica de clase un componente étnico novedoso. La acumulación de la experiencia movimientista de cara al Estado, sumada a la experiencia sindical de militancia, y al roce y negociación permanente con las dirigencias de los partidos políticos provinciales y nacionales allanaron parte del camino hacia la conformación del partido. El FUyO fue una traducción institucional de una acumulación histórica instituyente.

\section{El abanico de demandas desde la interseccionalidad}

En este apartado procuramos desentramar los tipos de experiencias que han confluido en un movimiento heterogéneo y polifacético, para reconstruir desde ese cruce las modalidades que van adquiriendo las distintas demandas y disputas generadas al interior de la sociedad jujeña, con su posterior alcance a controversias a nivel nacional. La intención es poder dimensionar el alcance que puede adquirir para la vida de las personas que atravesaron trayectorias de exclusión una praxis colectiva y comunitaria destinada a la viabilización de políticas de inclusión y reconocimiento.

Es necesario partir del supuesto de que en toda cultura existen "desprecios escalonados" (Rivera Cusicanqui 2010) por los cuales se van formando eslabones de diferentes tipos de violencias dirigidas a grupos minoritarios al interior de lo que podríamos reconocer como minorías dentro de una sociedad. $\mathrm{Si}$, por ejemplo, el racismo es una forma de opresión y autorrepresión (Wallerstein 1988), las violencias multiformes esgrimidas a partir de la condición de género parecen presentarse como inherentes e inseparables de las dinámicas sociales contemporáneas (Segato 2003). Ambas facetas, la violencia de género y el racismo, si bien pueden resultar distinguibles y caracterizables en la teoría, operan inextricablemente en la experiencia de precaridad de ciertos sujetos. Este ejemplo sirve para iluminar la diversidad de opresiones que se intersectan al pensar la etnia, la clase, la raza, la sexualidad, la identidad de género, la nacionalidad, la diversidad funcional y la edad como factores que inscriben otro tipo de experiencias, y que suelen exacerbarse en un cruce con la diferencia de género. El reconocimiento de este tipo de interseccionalidades (Crenshaw 1989) -la intersección de múltiples formas de opresión por características inextricables en un mismo sujeto- permite visibilizar las operaciones que jerarquizan las relaciones a partir de una multidimensionalidad de elementos reunidos en una misma persona. A partir de esta antesala, podemos comenzar a desandar el abigarramiento de experiencias intersectadas que comprenden y comprendieron al movimiento Tupac Amaru.

Desde los primeros años en las copas de leche o en las cooperativas, un vistazo evidenciaba el número significativo de mujeres presentes en la Tupac 
5. "El cantri de los pobres" es el nombre que recibe el barrio construido por la organización, en una parodia a los countries (urbanizaciones cerradas).
Amaru. Una buena parte de estas mujeres se dedicaron sobre todo a las tareas de construcción, convirtiendo estos espacios, para algunas, en una primera experiencia de trabajo remunerado fuera del hogar, y, para otras, de primer empleo estable en sus trayectorias. Además, gran parte de las mujeres en las obras no habían tenido, hasta el ingreso a la Tupac Amaru, experiencia previa en albañilería, herrería y construcción (Gaona y López 2013). La presencia mayoritaria de mujeres en las bases de la organización, la institucionalización a partir de la práctica de políticas de conciliación de tiempos y espacios de trabajo remunerado con las cargas domésticas y familiares, la permanencia por tiempos más prolongados por parte de las mujeres respecto de los varones en la órbita de la organización, además del evidente peso de la identificación con un liderazgo personalista como el de Milagro Sala, devinieron en que muchas de ellas ocuparan roles de liderazgo entre las capas medias de la Tupac, como presidentas de cooperativas y encargadas de obras, cargos jerárquicos pocas veces alcanzados por mujeres en el ámbito laboral, en la acción sindical, y en el trabajo popular y comunitario. Señalar que las mujeres emprendan y ocupen un rol destacado en cantidad y en jerarquías en lo que respecta al trabajo y a la militancia entre los sectores populares resulta de relevancia al considerar este factor a contraluz de una serie de medidas tomadas como parte del desenvolvimiento cotidiano de la vida en la Tupac Amaru.

Un gran número de las mujeres incluidas en los proyectos de construcción de viviendas fueron mujeres jóvenes, madres solteras, mujeres embarazadas, lesbianas y trans, analfabetas, ex presidiarias, mujeres con problemas de salud (vinculadas al sobrepeso, por ejemplo) y en un rango de edad que no entra dentro de los requisitos que se exigen habitualmente en el universo laboral privado. Asimismo, al acceder mayoritariamente a tareas de trabajo "no tradicionales" para las mujeres, muchas aluden al bienestar de no tener que responder cotidianamente a prescripciones culturales respecto de la imagen y la performance femenina en espacios públicos.

Un elemento clave para la incorporación laboral masiva de mujeres en la organización Tupac Amaru tiene que ver con el sistema comunitario de cuidado de la primera y segunda infancia enfocado sobre todo en los hijos e hijas de los cooperativistas de obras. Las salas para la infancia supeditaron su horario de cuidado a los horarios de trabajo de las obras de construcción, por lo que muchos adultos, beneficiando sobre todo a las mujeres, pudieron delegar el cuidado de los niños fuera del ámbito doméstico o familiar directo. Asimismo, en el cantri ${ }^{5}$, la disponibilidad del comedor comunitario y de las decenas de copas de leche en las distintas etapas del barrio permitía proveer de alimento a los niños de las familias del barrio. La posibilidad de acceso a infraestructura y servicios de apoyo para cubrir las necesidades de la infancia promueven el bienestar social y familiar, y generan mayores condiciones de igualdad en el acceso al trabajo remunerado entre mujeres y varones. Espacios comunitarios como estos permitieron armonizar la vida laboral y familiar/doméstica, y aminorar brechas socioeconómicas como de género (Gaona 2017). 
En una muestra realizada en 2010 , dos de cada tres mujeres que vivían en el cantri no habían terminado sus estudios secundarios, y en todos los casos el motivo aludido refería a la maternidad adolescente y las responsabilidades domésticas. La oferta educativa en los colegios de gestión social de la organización en todos los niveles a contra-turno de los horarios de trabajo se vio impulsada permanentemente por la presión personalizada de Milagro Sala con cada uno de los militantes, de acuerdo con los relatos acerca de la incorporación al sistema educativo.

Acerca del acceso a la vivienda y la conformación de hogares en el barrio construido por la organización, en el muestreo realizado, un $57 \%$ de los hogares eran de jefatura de mujeres solteras, viudas o separadas con hijos. Así, los hogares monoparentales femeninos constituían la morfología familiar más repetida en las viviendas. Gran parte de estas mujeres vivía con un solo hijo o hija. Este acceso tiene un peso inconmensurable que va más allá del dato numérico de reparación respecto del déficit habitacional, peso solo perceptible en el relato de sus trayectorias previas. Para muchas supuso la posibilidad de salida de relaciones familiares y de pareja violentas, de condiciones precarias y de hacinamiento, de la alternancia permanente entre viviendas, y de la conformación de un primer hogar con vivienda propia entre familias jóvenes.

El acceso a espacios de aprendizaje social de oficios, a empleos estables, a la vivienda, y a las garantías de educación y salud generaron las condiciones para que la Tupac Amaru además funcionara como un espacio de encuentro de personas de la comunidad LGBTIQ, un colectivo social altamente intersectado por las desigualdades materiales a partir de la diferencia. Partimos del supuesto de que el "Área de Diversidad"6 conformada en la Tupac no se trata de una segregación al interior del movimiento como trasgresión segmentada, sino que es producto del desenvolvimiento agente de las condiciones de reproductibilidad de la vida por parte de un conjunto de individuos que derivan de manera -no casualmente-colectiva en la Tupac. Esto supone asimilar buena parte de las acciones en concreto como resultado de una elaboración de transformación con raíz en la experiencia compartida.

Más allá de las posibilidades laborales y de acceso a bienes materiales y de otros derechos, para muchos militantes, la Tupac Amaru se ha elaborado como espacio alterado y distanciado de las lógicas heteronormativas más violentas, desde los espacios institucionales generados para la promoción del respeto y la valoración, hasta el desarrollo afectivo público más cotidiano entre militantes y obreros.

Las marchas del orgullo llevadas adelante por los militantes en 2013 y 2014 fueron las manifestaciones con consignas LGBTIQ más importantes que se hayan registrado en todo el noroeste argentino, con la participación de decenas de miles de personas. Estas marchas hibridaron prácticas carnavalescas de corsos de las zonas bajas, con apuestas de carrozas símiles a las del desfile de reinas de la Fiesta Nacional de los Estudiantes ${ }^{7}$-uno de los eventos más valorados y caros de la tradición local-, enalteciendo en ellas a reinas trans y a drags queens y kings.
6. Un movimiento social al interior del movimiento, que reunía a militantes identificados con las consignas LGBTIQ y procuraba funcionar como espacio de contención, liberación y empoderamiento, tanto de personas que pertenecían a la organización como de personas en distintos puntos de la provincia.
7. Esta fiesta de proyección nacional celebra la semana del estudiantado en septiembre y su agenda programa año a año, entre otras actividades, una elección nacional de reinas estudiantiles. 
8. El concepto de villero refiere a las personas que se asientan en las villas miseria. Si bien datan desde las primeras décadas del siglo $X X$, a partir de un marcado fenómeno de empobrecimiento hacia fines de ese siglo, se dio una marcada expansión, tanto de los habitantes de las villas, como de la cultura villera. La cultura villera contestataria tiene una estética propia que reivindica su lugar postergado y estigmatizado en la sociedad argentina (Muñiz 2009).
Y si bien, estos eventos son los más destacados públicamente en lo que respecta a las acciones militantes en torno a las sexualidades por parte de la Tupac Amaru, ambos son tan solo el desprendimiento de un proceso mucho más rico que se gesta prácticamente desde los inicios de la organización. En parte debido al acrecentado número de mujeres lesbianas que se reconoce desde los inicios entre las líneas fundadoras de la Tupac, en parte a partir de la apuesta por asumir la responsabilidad de la resolución de situaciones y problemáticas al interior de la comunidad LGBTIQ en la organización (filiales y de vínculos afectivos, legales, de acompañamiento, apoyo emocional y soporte laboral y económico), y del reconocimiento de consignas igualitarias para los militantes. Inclusive previo a la aprobación de la Ley de Matrimonio Igualitario a nivel nacional, ya se celebraban matrimonios entre parejas del mismo sexo durante la ceremonia anual del Inti Raymi (celebración andina en el solsticio de invierno).

La Tupac Amaru se ha valido de identificaciones estratégicas como procesos de reconocimiento auto-afirmativo en tanto encontró allí una vía para desandar opresiones múltiples y transversales. No podemos pensar al orgullo sexual y de género por fuera del reconocimiento afirmativo étnico o los méritos de lo obtenido desde las capas socioeconómicas más bajas sosteniendo y enalteciendo una reivindicación de clase popular villera ${ }^{8}$.

Parte de las vías más potentes de transformación y emancipación se dieron en dos caminos de lo practicado: en las alianzas transversales de resistencia estratégica a la norma (el lazo comunitario, la discusión de algunos indecibles, la rearticulación de lo experimentado) y en la reapropiación corporal de figuras hegemónicas por parte de cuerpos múltiples y bizarros que conmocionan la estabilidad de lo visible a nivel local. Estas estrategias no del todo planificadas pueden tener parte importante en la reacción del status quo contra ellas.

Para comprender al menos inicialmente una trama tan compleja como las identidades locales jujeñas, es necesario atender a los vaivenes históricos en la contienda local por la pertenencia nacional, desde una región de frontera con un alto índice de población indígena, inmigrante y descendiente de inmigrantes. Esto lleva, por ejemplo, a que el sentido común construido en torno de la capital provincial opere construyéndose a sí mismo mediante sentidos normalizados de una figura de localidad ideal abonada y restituida por los elementos más visibles, a partir de los cuales se caratula el delineamiento de identificación univoca pretendido por los sectores hegemónicos. Algunas articulaciones hegemónicas locales pueden sintetizarse en las escenas visibles que aportan a su constitución; entre otras, la Fiesta Nacional de los Estudiantes (desfiles de carrozas, elecciones de reinas), las conmemoraciones anuales de la gesta heroica patria del Éxodo Jujeño, el símbolo deportivo del club Gimnasia y Esgrima de Jujuy (el lobo jujeño), las celebraciones y peregrinaciones populares cristianas de la Virgen de Río Blanco y Paypaya.

Esta configuración ideal se presenta fenotípicamente blanca, argentina (en conflicto y negación con la proximidad boliviana), católica, gaucha heroica (coherente con el nacionalismo criollo del siglo XX) y con necesidad de lo ur- 
bano como contrapartida de aquel territorio/paisaje etnificado, patrimonializado y fronterizo, que suponen la puna y quebrada provinciales ${ }^{9}$.

Frente a esto, la Tupac Amaru restituye parte de los símbolos indígenas entre una comunidad mayormente urbana que hasta ese momento había rechazado o velado su pertenencia étnica. La espectacularización de lo indígena en la ciudad puede percibirse como signo eficaz, ante una operación urbana por desindigenizar la ciudad y por etnificar el interior provincial. La presencia, por ejemplo, de la réplica del templo de Kalasasaya como símbolo indígena, no es ni ornamental ni pintoresco, sino que trasciende como elemento crítico interno, como presencia incómoda que habla a partir de elementos construidos concatenadamente en comunidad. Esta noción de comunidad debe entenderse comprendiendo la configuración de un sector de la población que en gran medida se ve conformado por sectores migrantes que, por un lado, se vieron forzados a 'drenar' las regiones rurales de puna y quebrada como elementos ya fragmentados a partir de la operación crónica de confinamiento excluyente que marginalizó a los habitantes de esta región, tanto del proyecto político nacional como del provincial; $y$, por otro lado, por procesos más recientes de vaciamiento de polos productivos empresariales en la zona de las yungas y los valles más próximos.

A la luz de estas trayectorias marcadas por las carencias, estos excesos pueden leerse como una afrenta a la moral de la necesidad por la que transita la experiencia comunitaria de estos sectores. Entre el número, el gasto, la masa, la obra desmedida, no se percibe un aura de racionalismo envilecedor del esfuerzo, del desgaste o de la pérdida. Aunque existe un comportamiento agonístico, no parece ser el principal movilizador del derroche, sino que más bien puede advertirse como una promesa de concreción de algo inconmensurable (Bataille 1987).

Ciertas prácticas de reciprocidad y de lógicas de propiedad comunal de la Tupac fueron novedosas entre organizaciones sociales a nivel nacional, acercándola mucho a experiencias comunitarias andinas. Esto la convierte en una organización peculiar que supo combinar repertorios más comunes de protesta y de territorialización barrial nacionales con métodos de convivencia, de producción y de posesión diferenciadas, más cercanos a las experiencias andinas de las últimas décadas (Stefanoni y Do Alto 2006).

\section{Notas críticas acerca del contexto actual}

En razón del intercambio simbólico e interaccional entre los distintos sectores que se articulan alrededor de la Tupac Amaru, en el intercambio político jujeño se ha propiciado una acumulación discursiva a modo de afección diseminada. Instituciones y actores de las más diversas procedencias han sostenido y acrecentado un flujo permanente de precondiciones de sentido, sea aludiendo a sus métodos relacionales, aludiendo a la afluencia de recursos, a la disposición de ellos, a la monopolización de demandas, etc. La hipervisibilización que alcanzó en el plano público local devino en una diversificación de
9. Esta conceptualización se hace basándonos sobre todo en lo ya trabajado por Gaona 2015; Burgos 2014; García Vargas 2010; Ficoseco 2007; Caggiano 2005; Karasik 1994; Belli y Slavutsky 1994; entre otros. 
10. Expedientes de las causas federales y provinciales: 127.785/2015; 129.652/2016; 131.072/2016; 18.487/2016; $74.000 .120 / 2011$

$86.175 / 2014 ; 552 / 2009$; $398 / 2011 ; 2.990 / 2012$. las afecciones hacia ella. Por otro lado, la asimetría en el reparto de discursos visibles -por ejemplo a nivel mediático masivo- ha operado como coerción permanente que ha logrado poner el foco en la necesidad de intervención política gubernamental sobre la convivencia y la productividad en los espacios construidos por la organización, llegando a alcanzar al desposeimiento absoluto por parte de los militantes.

La Tupac Amaru ha ostentado no solo la aparente monopolización de los recursos económicos nacionales destinados a la acción colectiva en la provincia y la hegemonización de las demandas de distintos sectores sociales, sino también, y de manera más destacada, la monopolización de un nudo sensible de las fibras de la violencia social. La interpretación acerca de ciertas economías del odio no pueden leerse en términos de clase o en términos raciales, únicamente, sino que se tiene que observar el modo acumulativo por el cual se anudan ofuscaciones acerca de la Tupac entendida como una multitud peligrosa.

Este estado de conflicto visible ha permitido activar las maniobras para la restauración de un reequilibrio histórico. La derrota gubernamental partidaria que sostenía económicamente a la organización, y un período de desgaste y polarización permitieron reflotar a nivel colectivo una aparente necesidad de refundación convivencial. La condición para llegar a una homogeneización social y al consenso se hace a expensas de que la cultura pública hegemónica resuelva la convivencia mediante el dictamen de la necesidad de la 'eliminación' del antagonismo. Según esta apreciación sacrificial de aquello que genera conflicto, recién se puede concebir a nivel local la convivencia democrática una vez expulsada la diferencia (Butler y Spivak 2009).

Para diciembre de 2016, frente a un cambio de gobierno a nivel provincial y nacional, la organización se manifiesta de manera pacífica frente a la casa de gobierno provincial en busca de una confirmación del sostenimiento de los programas de construcción de viviendas. Como respuesta a esta vigilia, el nuevo gobernador, Gerardo Morales, decreta en enero de 2017, el retiro de la personería jurídica de la organización, la imposibilidad de acceso a planes sociales y programas productivos por parte de todos los cooperativistas presentes en la plaza, proponiendo "liberar a aquellas personas y familias que fueron utilizadas como rehenes del viejo sistema" (Decreto pcial. 403$\mathrm{G}$ /2016). Por otro lado, a nivel judicial, se dispone la detención de Milagro Sala con la carátula penal de "Sedición e instigación a cometer delito", y la contravencional de "Ocupación del espacio público, alteración de orden y obstrucción del tráfico".

Se le suceden a estas, denuncias que nutren el abanico de sentidos locales acerca del mal social que supone Milagro Sala y la Tupac Amaru. Es acusada de Fraude y Asociación Ilícita, Lesiones Graves, Daño Agravado y Amenaza, Daño a la Propiedad Pública, y Tentativa de Privación de la Libertad ${ }^{10}$. Desde enero de 2017 ha sido enjuiciada por tres de las causas mencionadas, pero se encuentra aún sin condena definitiva. 
Por ello, y por la gravedad de su situación de detención preventiva, se sucedieron rápidamente pronunciamientos y solicitudes internacionales respecto del estado arbitrario de su detención. Entre ellas, la Comisión Interamericana de Derechos Humanos le ha otorgado la medida cautelar considerando que se encuentra en una situación de gravedad y urgencia, y la Corte Interamericana de Derechos Humanos ha ordenado que se procuren medidas de protección para garantizar la vida y la integridad de la líder encarcelada.

De acuerdo con el trabajo en entrevistas y grupos focales durante 2016 y 2017, buena parte de las mujeres y varones cooperativistas de la organización se encuentran en un nuevo escenario de inestabilidad y vulnerabilidad social, basado en la fragilidad de sus posibilidades de acceso al trabajo remunerado, y en una nueva capa de discriminación basada en la pertenencia e identificación con un movimiento señalado y estigmatizado (Tabbush y Gaona, 2017).

Estas notas se plantean al final del artículo como presentación metonímica pero paradigmática de la situación actual de los movimientos populares en la región, frente a lo que Vommaro (2017) denomina el "cambio cultural", la nueva centroderecha argentina.

\section{Conclusiones}

Hemos intentado presentar a partir de una progresión histórica, el desarrollo de una organización social que puede influir en redefiniciones fundamentales a la hora de analizar los movimientos sociales populares latinoamericanos. La interseccionalidad de sus demandas y las operaciones rizomáticas que la llevaron a ubicarse como catalizadora de conflictos históricos y presentes de toda una región hablan a las claras de un proceso múltiple y denso que merece de una pormenorizada atención a la luz de los sucesos acontecidos.

Parte de lo analizado en los primeros segmentos de este artículo fue releído y modificado a partir de las transformaciones más recientes, en razón de superar ciertos simplismos en el análisis. Se destaca de manera más evidente, el modo en el que la estructura estatal incide en todas las instancias posibles de desarrollo de un movimiento popular, sea de manera directa, a través de la vehiculización de fondos, como de manera indirecta, sencillamente, dejándolo acontecer. Una interpretación posible de lo que aconteció en los últimos años puede observar que ciertamente a nivel nacional los peronismos se han caracterizado por, sino tutelar, más bien 'dejar hacer' a ciertas movimientos en aras a la transformación. Es así que se propaga y extiende una organización de estas magnitudes, hasta detentar un contrapoder inaudito en la productividad social de cara a los aparatos estatales.

Como se demuestra en el apartado acerca de las demandas perseguidas, la confluencia y el abigarramiento de experiencias de exclusión en un colectivo como el estudiado muestra cómo espacios productivos con agendas equitativas pueden resultar en propulsores de transformaciones trascendentales, 
tanto en lo que refiere a las condiciones concretas de desarrollo de la existencia como de reparación y reconocimiento en clave afirmativa por parte de las personas involucradas. La magnitud alcanzada ha llevado a conseguir disputar desde un plano visible que trastoca e incomoda al status quo local, sobre todo en lo que respecta a los poderes articulados vinculados al género, la clase, la etnia y las sexualidades, todas ellas sostenidas desde un plano moral. Las consecuencias culturales de este fenómeno se vieron galvanizadas por fuera de la Tupac Amaru en un sentimiento de afección diseminado entre actores, instituciones y demás sectores populares.

También debe hacerse mención en estas conclusiones a la evidencia material de las dificultades que acarrean los populismos personalistas y verticalistas, propiciando, a la par de la virtud de la inapelable identificación con una líder, la tara de la facilidad con la que se deja acéfalo a un movimiento de decenas de miles de personas.

Queda como excepcionalidad del curso de la historia un movimiento que supo valerse de los recursos de una época para producir materialidades en exceso, inadvertidas inclusive para los poderes políticos tradicionales que, al advertirlo, consintieron su impulso. Esa excepcionalidad del hacer masivo concretó sus mayores virtudes y complicaciones en la ponderación de un liderazgo femenino inaudito.

\section{Bibliografía}

Bataille, Georges. (1987). La parte maldita. Madrid: Icaria.

Battezzati, Santiago. (2012). La Tupac Amaru: intermediación de intereses de los sectores populares informales en la provincia de Jujuy. Desarrollo económico, 52 (205), 147-171.

Belli, Elena y Ricardo Slavutsky. (1994). Flores, reinas y carrozas. Reflexiones sobre la identidad en San Salvador de Jujuy. En Cultura e identidad en el noroeste argentino, comp. por Gabriela Karasik (120145). Buenos Aires: Centro Editor de América Latina.

Bergesio, Liliana, Laura Golovanevsky y María Elene Marcoleri. (2009). Privatizaciones y mercado de Trabajo: La venta de empresas públicas en Jujuy y sus consecuencias sobre el empleo. En Jujuy bajo el signo neoliberal. Política sociedad y cultura en la década del noventa, dirigido por Marcelo Lagos, (185-249). San Salvador de Jujuy: EDIUNJu.

Burgos, Ramón. (2014). Fútbol y política. El club Gimnasia y Esgrima y la construcción de una identidad jujeña (1975-2011). Tesis doctoral. Universidad Nacional de La Plata. http://hdl.handle.net/10915/43419

Butler, Judith y Gayatri Spivak. (2009). ¿Quién le canta el Estado-Nación? Lenguaje, política y pertenencia. Buenos Aires: Paidós. 
Caggiano, Sergio. (2005). Lo que no entra en el crisol: inmigración boliviana, comunicación intercultural y procesos identitarios. Buenos Aires: Prometeo libros.

Crenshaw, Kimberle. (1989). Demarginalizing the Intersection of Race and Sex: A Black Feminist Critique of Antidiscrimination Doctrine, Feminist Theory and Antiracist Politics: en University of Chicago Legal Forum, Vol. 1989, I, 8.

Dujovne Ortíz, Alicia. (2017). Milagro. Buenos Aires: Marea Editorial.

Ficoseco, Verónica. (2007). La construcción de la imagen de la mujer en la prensa gráfica de Jujuy durante la Fiesta Nacional de los Estudiantes. Tesis de licenciatura. Universidad Nacional de Jujuy.

Gaona, Melina. (2016). Experiencia, ciudad e identidad en torno a la organización barrial Tupac Amaru. Tesis doctoral. Universidad Nacional de La Plata. http://hdl.handle.net/10915/52003

Gaona, Melina y Andrea López. (2013). Género, comunicación y cultura. En dos organizaciones sociales de San Salvador de Jujuy. San Salvador de Jujuy: EDIUNJu.

García Vargas, Alejandra. (2009). Geografías del poder. Comunicación transnacional y estudios interculturales en la periferia globalizada en Memoria Encuentro Internacional Comunicación y Cultura "Interculturalidad, globalización y comunicación". La Paz: Fundación Visión Cultural.

García Vargas, Alejandra. (2010). San Salvador de Jujuy: una, otra, esta ciudad. En Ciudad. San Salvador de Jujuy como texto, comp. por Alejandra García Vargas. San Salvador de Jujuy: EDIUNJu.

Giorgetti, Daniel. (2015). Trabajo, militancia y juventud en Argentina. Una perspectiva histórica. Ponencia presentada en la XI Reunión de Antropología MERCOSUR 2015.

Karasik, Gabriela y Elizabeth Gómez. (2015). La empresa Ledesma y la represión en la década de 1970. Conocimiento, verdad jurídica y poder en los juicios de lesa humanidad. Clepsidra, 3, 110-131. Acceso el 20 de enero de 2017. http://memoria.ides.org.ar/revistaclepsidra/clepsidra-no-3

Karasik, Gabriela. (1994). Plaza grande y plaza chica: etnicidad y poder en la Quebrada de Humahuaca. En Cultura e identidad en el noroeste argentino comp. por Gabriela Karasik. (pp. 35-75). Buenos Aires: Centro Editor de América Latina.

Karasik, Gabriela. (2005). Etnicidad, cultura y clases sociales. Procesos de formación histórica de la conciencia colectiva en Jujuy, 1970-2003. Tesis inédita de doctorado. Universidad Nacional de Tucumán.

Kindgard, Federico. 2009. Los conflictos sociales bajo la política neoliberal. En Jujuy bajo el signo neoliberal. Política, sociedad y cultura en la 
década del noventa, comp. por Marcelo Lagos, (311-355). $2^{\circ}$ Ed. San Salvador de Jujuy: EDIUNJu.

Lagos, Marcelo y Mónica Gutiérrez. (2009). La década del menemismo y la ingobernabilidad en Jujuy. Nación, región y provincia en los noventa. En Jujuy bajo el signo neoliberal. Política, sociedad y cultura en la década del noventa, comp. por Marcelo Lagos, (65-124). $2^{\circ}$ Ed. San Salvador de Jujuy: EDIUNJu.

Lagos, Marcelo y Mónica Gutiérrez. (2006). Dictadura, democracia y políticas neoliberales. 1976-1999. En Jujuy en la historia. De la colonia al siglo XX, dir. por Ana Teruel y Marcelo Lagos, (243-294). San Salvador de Jujuy: EDIUNJU.

Martinez, Ricardo, Laura Golovanevsky Fernando Medina. (2010). Economía y empleo en Jujuy. Colección Documentos de Proyecto. Santiago: CEPAL.

Muñiz, María Gabriela. (2009). Protagonismo villero: la nueva fisonomía de una Buenos Aires marginal en la segunda mitad del siglo XX. En Nuevo Mundo Nuevos Mundos. Acceso el 20 de enero de 2017. http://journals.openedition.org/nuevomundo/57742\#quotation

Rivera Cusicanqui, Silvia. (2010). Violencias (re) encubiertas en Bolivia. La Paz: La mirada Salvaje.

Rodríguez Blanco, Mariela. (2002). La parte de los que no tienen parte. La dimensión simbólica y política de las protestas sociales: la experiencia de los piqueteros en Jujuy. Buenos Aires: Centro Cultural de la Cooperación.

Segato, Rita. (2003). Las estructuras elementales de la violencia. Bernal: Universidad Nacional de Quilmes.

Stefanoni, Pablo. y Havre Do Alto. (2006). Evo Morales de la coca al Palacio. Una oportunidad para la izquierda indígena. La Paz: Malatesta.

Tabbush, Carolina. y Melina Gaona. (2017). Gender, race and politics in contemporary Argentina: Understanding the criminalization of activist Milagro Sala, leader of the Organización Barrial Tupac Amaru. Feminist Studies, 43, 2.

Vommaro, Gabriel. (2017). La centroderecha y el 'cambio cultural' argentino. Nueva Sociedad, 270, Julio-Agosto: 4-13. Acceso el 16 de junio de 2018:

http://nuso.org/media/articles/downloads/COY1_Vommaro_270_bsT5zY x.pdf

Wallerstein, Inmanuel. 1988). El capitalismo histórico. Madrid: Siglo XXI Editores. 